This item was submitted to Loughborough's Research Repository by the author.

Items in Figshare are protected by copyright, with all rights reserved, unless otherwise indicated.

\title{
Re-constituting social, emotional and mental health difficulties? The use of restorative approaches to justice in schools
}

\section{PLEASE CITE THE PUBLISHED VERSION}

http://www.palgrave.com/page/detail/childrens-emotions-in-policy-and-practice-matej-blazek/?

K=9781137415592

\section{PUBLISHER}

Palgrave Macmillan

\section{VERSION}

AM (Accepted Manuscript)

\section{PUBLISHER STATEMENT}

This work is made available according to the conditions of the Creative Commons Attribution-NonCommercialNoDerivatives 4.0 International (CC BY-NC-ND 4.0) licence. Full details of this licence are available at: https://creativecommons.org/licenses/by-nc-nd/4.0/

\section{LICENCE}

CC BY-NC-ND 4.0

\section{REPOSITORY RECORD}

Lea, Jennifer, Louise Holt, and Sophie Bowlby. 2019. "Re-constituting Social, Emotional and Mental Health Difficulties? the Use of Restorative Approaches to Justice in Schools". figshare. https://hdl.handle.net/2134/18213. 
Talking about socio-emotional differences, constituting Social, Emotional and Mental Health Difficulties? The use of restorative approaches to justice in schools.

Jennifer Lea (University of Exeter)

Louise Holt (Loughborough University)

Sophie Bowlby (University of Reading)

Jennifer Lea, Geography, College of Life and Environmental Sciences, University of Exeter, Rennes Drive, Exeter, EX4 4RJ.

j.lea@exeter.ac.uk

07966459056

Word count: 5751 


\section{$\underline{\text { Introduction }}$}

The inclusion of children with special educational needs (SEN) in mainstream schools is seen to be beneficial to all students; as Alur and Timmons (2009, ix) suggest 'if we can successfully provide education to our most vulnerable children the education of all children will improve'. The inclusion of certain 'vulnerable' children however, particularly those with socio-emotional differences, troubles this assumption. Many young people with socioemotional differences who participated in the research were diagnosed, under the SEN Code of Practice (2001) as having Behavioural, Emotional and Social Difficulties, or BESD. The new SEN Code of Practice came into force in the UK in September 2014, and involves a change of labelling of this category of SEN to 'Social, emotional and mental health difficulties'. Here we use the term socio-emotional differences because it emphasizes the embodied experience of feeling different in a specific place, and that these differences emerge in specific normative contexts.

Socio-emotional differences are often poorly understood and engender negative responses in schools; educators do not know how to respond to students whose particular SEN 'seems to justify punitive disciplinary action' (Jull 2008: 13). In this chapter we examine one response that has grown in significance in UK schools; the use of restorative approaches to justice (RJ). Such approaches have been translated from the criminal justice system. They offer an alternative to disciplinary action, and aim to help students resolve difficulties in their relationships. Strong claims have been made on behalf of restorative approaches which include the production of 'calmer schools' with less exclusion (McCluskey et al. 2011: 106). This chapter offers a UK-specific perspective on the relations between emotions and policy in the context of education. It seeks to situate individual school-based interventions, employed to deal with 'problematic' emotions, within the wider UK policy framework around 'Social And Emotional Wellbeing' (Watson et al. 2012). The chapter draws upon research undertaken in a special unit for students designated as having BESD, and argues that restorative approaches used within the unit offer an opportunity to value and include the emotionally, behaviourally and 
socially pathologised unit members. After outlining socio-emotional differences and the current thinking on $\mathrm{RJ}$, the chapter briefly introduces the case study and methods before discussing the use of $\mathrm{RJ}$ in the unit and wider school.

\section{Behavoural, emotional and social differences.}

While the numbers of young people with BESD are relatively large and increasing, critical educational literature has been relatively slow to offer reflection on these diagnoses (although see Benjamin 2002; Holt 2010; Youdell 2006, 2011). The UK government definition of BESD suggests that these students are variously 'withdrawn and isolated, disruptive or disturbing, hyperactive and lacking concentration, [with] immature social skills, presenting challenging behaviour arising from other complex special needs' (Department for Education and Skills 2008: 87). In common with any diagnoses, that of BESD requires interrogation because it is not 'simply descriptive' but acts to 'constitute and limit who those students are' (Youdell 2011: 78). By virtue of a diagnosis, pupils are 'rendered outside the normative centre of subject, learner and subjecthood' (Youdell 2006: 126) because their emotions, social relations and behaviour are seen to be 'out of place' within the school context. Such pupils often occupy a subordinate position within the educational institution and schools remain broadly exclusionary spaces for pupils with BESD.

In a paper on emotional management in UK schools, Gagen (2013: 3) argues that 'emotional competency is becoming the new benchmark by which young people are marked as successful subjects'. Emotions, variously conceived (for instance via Goleman's notion of emotional intelligence in SEAL (Watson et al.), or psychodynamic models of the subject (Lea et al. 2013)), are increasingly positioned as an area in which interventions can be made. This is encouraged and positioned via a number of formal and informal mechanisms across school spaces at a number of scales (Bowlby et al. 2014); for instance, classroom based norms of student emotions and socialities, school based 
discipline systems and strategies of self-management, and national strategies such as SEAL (Social and Emotional Aspects of Learning; which, while no longer promoted by the Department of Education was still used in schools at the time of the research). This has been understood as a shift towards discourses of 'social and emotional wellbeing' (Watson et al. 2012); a collection of strategies and policies shaped by positive models that aim to optimise social and emotional wellbeing and negative models that target emotional states and forms of expression seen as problematic.

Emotions have thus become an increasingly significant lens through which staff and pupils have come to understand themselves and others. At the same time, norms of emotional expression have become formalized in documents at national, local and school levels. Seemingly without coincidence, the numbers of pupils with BESD have increased; Department for Education figures (2011: 69) show an increase of $23 \%$ (to 158,000) between 2005 and 2010 . While the links are undoubtedly complex and multidimensional, the norms of emotional expression produced and reproduced by such discourses and practices are often seen as unobtainable for students with BESD. Such notions and norms of emotional competency and expression need to be critically interrogated along the lines of class, gender, race and sexuality in order to understand what particular forms of subjectivity are being privileged by them.

Youdell (2011: 80) argues that BESD can be mapped onto a form of 'working class masculinity that is unwelcome in mainstream schools and at odds with dominant notions of proper student behaviour'. Additionally, the wider research within which this chapter is situated found that other subjectivities were othered (e.g. via norms of student behaviour (e.g. Holt et al. submitted), and indeed by definitions of BESD (especially in the case of gender)). The link between certain kinds of subjecthood and BESD often means that problematic emotions and behaviours are understood to be embedded within the student and their home lives (e.g. the above UK government diagnosis). Students with BESD often become understood as intrinsically difficult or challenging, which can make them irredeemable within the school 
environment: 'incapable of behaving in more student appropriate ways' (Youdell 2011: 80). Such understandings aid the reproduction of the (problematic) dominant representation of BESD as an individual pathology (Holt 2010), and direct attention away from the question of whether exclusionary practices exist within schools. As mentioned in the introduction, we use the term 'socio-emotional differences' in order to problematise the straightforward location of the 'difficulties' within the young person and to acknowledge that they are socio-spatially constituted within schools as well as within homes and families (Holt 2010, Holt et al. 2012).

\section{$\underline{\text { Restorative Justice }}$}

Restorative approaches to justice bring 'offenders' and their 'victims' together (with a mediator) so that they might discuss harm, agree how it might be repaired, and reduce the risk of reoffending. Using a number of different strategies, communication between parties is facilitated (often using scripts or sets of questions) in order to establish what happened, what the parties were thinking and feeling at the time and since, who has been affected and in what ways, and what needs to be done to make the situation right (see McClusky et al. 2008: 202-203). These strategies are designed so that all members of the process are given the same opportunity to speak. RJ in schools has been seen to offer a 'non-pathologising' approach to behaviour (McCluskey et al. 2008), which contextualizes it and interrogates what the individuals involved were thinking, feeling and doing at the time.

RJ could be seen as a route to include students with socio-emotional differences in schools because it illuminates (and thus gives the opportunity to address) socio-spatial barriers to behaviour (and thus learning); the focus is shifted onto: 'systemic or structural issues which may give rise to inappropriate or disruptive behaviour, and from a focus on students alone to the larger question of relationships between all members of a school community' (McCluskey et al. 2011: 113). In its ideal form, the process is visible and involves multiple participants so all members of the community can learn from 'harm' done, such that 'responses to difficult behaviour have 
positive outcomes for everyone' (McClusky et al. 2008: 211). Whole-school ethos building along restorative lines is seen as the best mode of implementation, in contrast to the isolated use of $\mathrm{RJ}$ in response to individual misdemeanours.

Despite these promising accounts of restorative practice, there have been some more critical evaluations. Firstly, the use of a vocabulary from the criminal justice system arguably runs the risk of reinforcing 'a discourse that demonises and criminalises young people in general' (2008: 204), and this might be particularly pertinent if $\mathrm{RJ}$ is applied exclusively to pupils with socioemotional differences. Secondly, because clear punitive consequences are removed from actions, $\mathrm{RJ}$ is understood to complicate understandings of acceptable behaviour. RJ has been critiqued for not being 'tough' enough on students leading to the worry that teacher-pupil relationships are refigured to the teacher's disadvantage. Thirdly, RJ is risky if not used according to best practice recommendations; the experience of shame by the 'offender' is integral to the restorative approach but this is potentially problematic, especially if staff are not well enough trained to 'manage' this. Finally, the closed community of a school means that parties involved are likely to see each other on a frequent basis. This differs from wider society where the 'victim' and 'offender' may be less likely to meet, so the consequences of this different context must be negotiated.

\section{The case study and methods}

This chapter draws on data from a wider research project which explored the links between children and young people's social relationships and (dis)ability. It examined how everyday practices of young people in school, home and leisure spaces reproduce disability as a variously valued or devalued identity position, and how this intersects with other forms of social difference (class, gender, ethnicity and so on). Full details of the full project are available at the project website: http://www.socialcapital.Iboro.ac.uk.webhost1.lboro.ac.uk/ This chapter draws on in-depth qualitative research, consisting of participant observation of school and leisure spaces and in-depth interviews with 
students and teachers in one case-study school with a special unit for young people diagnosed with BESD. The chapter focuses upon ethnographic observation in the school, which took place over a period of 30 days was, with time spent observing across formal and informal spaces. These observations were overt and the students had received written and verbal information about the project, and were able to dissent to being observed. We also conducted semi-participatory research with approximately 12 students in each school, although this is not the focus of this chapter.

The case-study school is a Secondary (11-18) located in a relatively small rural LA in South East England. Pupils are drawn from the school's rural catchment and also the urban fringes of a large nearby town. Within this LA, there is no specific long-term alternative provision (e.g. a special unit or a special school) for young people with socio-emotional differences. The LA has a 'zero exclusion' policy meaning that schools cannot exclude pupils. If a school feels that they cannot meet the needs of a pupil they are referred to a 'managed move' panel which meets monthly to decide whether the school has made all the interventions that they can. If they have, the pupil is moved to another school for a 6 week trial. The panel effectively audits the school's abilities around socio-emotional differences (and other forms of SEN), and means that the onus is on the schools to come up with effective responses for young people with socio-emotional differences. The inclusion unit examined here is one such school-based solution.

\section{The inclusion unit}

\section{INSERT PHOTO 1 HERE}

The inclusion unit is a special provision within the mainstream school, to support students who are seen to be at risk from exclusion. This inclusion unit is based in a small room (see photo 1) and has 2 dedicated staff; an inclusion manager (IM) and an inclusion assistant (IA) who spend all their time in the unit. The Unit was established due to a 'growing number of students with socio-emotional differences which presented a barrier to their education' (this 
quote is taken from a document prepared by the school for the National Teacher Research Panel - a full reference cannot be given as it would identify the school). At the time of the research the unit had 12 members, some of whom had joined from the wider school and others via managed moves from other schools. Members come to the unit to register in the morning and after lunch, then follow their personalised timetables which offer a mix of lessons some in mainstream classrooms with subject specialist teachers and their peers, and others in the inclusion unit. Additionally members are often sent, or choose to come, to the inclusion unit if their mainstream lesson is problematic.

\section{Understanding socio-emotional differences}

The unit members were understood by pupils and staff to have "deep seated and fundamental" difficulties, which are understood to stem from their upbringing, families and communities. This broad understanding can be seen in this extract from the interview with Mr Lonsdale (the assistant head with responsibility for vulnerable pupils):

the kids who are the most disaffected and struggle the most have real problems with communication, which are started at the home from the moment they were born, and tend to come from, if I was going to typify our most disaffected kids, they come from you know lower socioeconomic backgrounds, with parents who have very poor communication skills themselves, who resort to yelling, shouting, F-ing and blinding rather than discussing, and that's the environment they're brought up in and that's all they know.

This echoes the literature on SEN, which notes that there is a long tradition of seeing 'parents as problems and contributing to their children's difficulties in learning' (Croll 2001 in Norwich et al. 2005: 151-152). This is particularly true for BESD as the 'additional need' for targeted help from within or beyond the school is constructed as resulting from 'interactions between parents and carers and young people, and the parental expectations of education' (Watson et al. 2012: 180; see also Holt, 2010). In some ways, this understanding serves to de-pathologise the pupils in the unit by underlining that they are not choosing to display socio-emotional differences. However, it 
still fundamentally locates the lack within the pupil (and their family), meaning that the school's role in constituting BESD is not (fully) acknowledged. Such understandings also reinforce the classed and gendered discourses that circulate around BESD, because, as Mr Lonsdale remarks, their home environment, and the problematic emotional, social and behavioural responses that are seen to emerge from it, are "all they know". These ways of understanding BESD, and the unit members, are fundamental to the ways in which the school members respond to these socio-emotional differences.

\section{$\underline{\text { Talking about socio-emotional difference }}$}

\section{INSERT PHOTO 2 HERE}

At the start of the day, the students make hot drinks and help themselves to snacks provided within the unit, while the IM and IA talk to them about how they are and what they've done the previous evening. Similar conversations are repeated throughout the day, and these were initially interpreted as students distracting the adults. However, over time a different understanding emerged; the staff use the conversations strategically to gather information, frame actions and model communication. For example, these conversations with Don (a year 11 boy just coming to the end of his compulsory schooling requirements) show an implicit framing of events in restorative terms:

When talking about what they were doing that evening Don had said it is his mum's birthday so he is going to go to [the chemists] to buy her some perfume - it costs £35. Or he can wait till the weekend and get two bottles for the same price but these will have been nicked by his mates. The IM asks him what his mum would think about this and then has a conversation about stealing. Don said that he had been with people who had been barred from the nearby supermarket for stealing and he was also barred. But he had not actually done the thieving ... They then go on to talk about someone who had been sitting where Don was this time last year and is now in prison for stealing (Don 
disputes this as apparently the lad was on Facebook this morning). (research diary, $29^{\text {th }}$ January).

They had had a chat about what he'd done the previous night - he'd hung around the shops for $21 / 2$ hours. He said he couldn't decide what to buy. The IM asked if he thought it was an intimidating thing to do and he said maybe, but he went into the shop and bought things so they were customers. She said did he wear his hood up, and he said he didn't see the point apart from when it's raining (research diary, $25^{\text {th }}$ January).

In both instances the IM and Don discuss what is and isn't appropriate behaviour, the IM outlines the consequences of Don's actions for other people, for his relationship with his mum, and for his future. Don isn't a passive recipient of this, but instead contests the classed and gendered discourse that the IM mobilises when she says that hanging round the shop is intimidating.

The conversations also allowed the staff to gather information about the students, and the underlying factors that they considered might contribute to, or exacerbate, socio-emotional differences. An example of this might be lack of breakfast:

Joe does a presentation ... for us. Afterwards he says his stomach is sore. It turns out (after some questioning from the IM and IA) that Joe hasn't eaten and he doesn't have any money. He lost some on the bus and used his last pound to buy himself a drink. He makes himself a cup of tea and the IM asks him if he gets free school meals (he doesn't) then she phones up the office to see if there is a fund for emergencies ... apparently the heads of house used to have money for this but they do not any more. Then the IM phoned reception back and they said they could add some credit to his account so she sent him down to sort this out. When he had left the room, the IM and IA say they are worried about Joe and that he should get free school meals. They want to get to the bottom of it (research diary, $25^{\text {th }}$ January). 
Mark's mum has come upstairs to the unit (she works downstairs in the school kitchens). The IM has been trying to sort out beds and bedding for Mark and his brother's room. The cover IA listens and then chips in and says she has a double mattress that she was going to throw out. Mark's mum arranges to pick it up. (research diary, $16^{\text {th }}$ March).

The inclusion staff develop a close knowledge of the pupils lives via such conversations, which allow them to intervene in issues that they see to be beyond the capacity of the students, or their parents/carers to solve. This kind of relationship and conversation is made possible partly because of the 'unschool'-like nature of the unit and partly because of the un-teacher-like status of the staff.

The unit is not straightforwardly recognizable as part of a school either in terms of the material space or the 'practices of both students and teachers' (Youdell 2011: 76). The arrangement of the chairs in a circle around a table is based on restorative principles (perhaps also reflecting the limited space in the unit), designed to enable everyone to take part in conversation and to reduce confrontation. Even when conversations didn't directly involve everyone in the room, they were 'public' so that everyone could listen/speak and learn from them. The tea area and tin (which held student's mobile phones, cigarettes and lighters) also underlined the differences. In contrast the with the rest of the school, the unit members were allowed a free choice period (in which they could play games or spend time on the computer) at the end of the day if they had had a good day. The unit staff were also less strict about swearing than teachers in the mainstream spaces of the school.

The restorative way of working employed in the unit was also facilitated by the fact that the IM and IA were not teaching staff. The research diary records the $I M$ and IA informing us 3 or 4 times that they were not teachers during the fieldwork period, and was important in the formation of a different relationship with the students. The IM and IA explained this in terms of parenting roles; the IM being the "authority", while the IA took a more "nurturing, mothering" role. As such, they explained that they provided "positive adult role models that [the students] haven't had from an early age" (research diary, $8^{\text {th }}$ February), and 
they saw their interactions with each other (and other adults) as modeling 'good relationships'. This parenting role has been understood as an 'ethic of care' (Beauchamp and Childress 2001, in Watson et al. 2012: 195) in which caring 'refers to care for, emotional commitment to, and willingness to act on behalf of persons with whom one has a significant relationship'. While this ethic of care has clear benefits for the unit members it could, at the same time, be seen to devalue the parenting cultures of the unit member's families (which, as noted above, are understood to be fundamental causes of socioemotional differences).

\section{$\underline{\text { Valuing socio-emotionally different relationships and identities }}$}

Given the centrality of relationships to $\mathrm{RJ}$, a lot of work done in the unit (explicitly and implicitly) is in this area; the IM and IA put a lot of effort into building the capacity of the unit members to have better relationships outside the unit and helping them repair relationships that had been damaged:

Will is ... print[ing] out an invite for someone to entertain for a cup of tea ... in the unit ... Will chooses a teacher he hasn't got on with as he wants to make amends and show him another side of himself (research diary, $25^{\text {th }}$ January).

Just as no relationship was seen to be beyond repair, neither were the identities of the unit members irredeemable. The IM and IA did work with the unit members to enable them to understand themselves in more valued terms. For example, they talked about the unit members in predominantly positive terms (after the conversation about his mum's birthday, the IM told us that Don is "a lovely young man who basically needs to make the right decisions" (research diary, $25^{\text {th }}$ January)). These positive statements were echoed in the displays in the unit (see photos 3 and 4 ). In turn this opens up the potential for the unit members to value themselves more than home or the wider school often allows, as this extract from the research diary shows: 
IM: did you show your mum the work you've done? [yesterday she had encouraged Don to take a photo of his GCSE English Coursework to take home to show his mum]

Don: she said "that ain't yours". I said "it is, why do not you believe it's mine?" Then she said "because you're having a fit about it I believe it's yours"

IM: then what did she say?

Don: she was surprised. I do not know why I can't do this in lessons" (research diary, $25^{\text {th }}$ January).

Underpinning this restorative work around relationships is the fundamental principle that unit members are valuable members of the school community, their identities and differences are acceptable and, as such, they deserve to have their needs met. The wider critical disability literature argues that the mainstream tends to position difference as a personal deficit through the dominant discourse of subjection (meaning that individuals who are categorised as different become socialised to think of themselves as inferior, see Shakespeare 1996). Being categorized via differences can lead to a 'discourse of need' rather than a 'discourse of the person' (Watson et al. 2012: 186), which tends to emphasise deficit and disadvantage, locating the 'problem' within the person and seeing them primarily as a diagnosis of socioemotional difference. The work done in the inclusion unit contributes to this, allowing members to access different understandings of themselves which let them 'place a more positive value' on themselves (Morris 1991: 28, in Shakespeare 1996) and counter the dominant discourse of subjection. On looking outside the unit to the mainstream spaces of the school, however, the discourse of the person has less credence and is replaced by discourses of need.

Reproducing Behavioural, Emotional and Social difficulties 
Despite the interventions already described, unit members often still had difficulties in mainstream lessons. About five or ten minutes after a lesson had started, multiple students would return to the unit from their mainstream lessons. This was such a regular occurrence that the students expected to see the other unit members come back up to inclusion:

Ava comes back up - Don and Will say didn't we tell you she'd be back up here ... She slumps in a chair and then announces that 'she' [the teacher] took her phone charger off her. She is visibly stressed out and wound up and says she is really fed up (research diary, $29^{\text {th }}$ January).

The students themselves reproduce the wider discourse that they are not appropriate students and cannot behave properly within the school context. As such, even while they are still in the inclusion unit they begin to contradict the work done by the staff to recuperate their problematic identities.

The unit staff and students were in agreement that because they were part of the inclusion unit, the members were assigned a 'problematic' reputation in the mainstream spaces of the school. This in turn was understood to mean that they received unfair treatment:

Something has kicked off in the previous lesson with Don. IA asks 'why do the teachers pick on you?' Don replies 'reputation, reputation. It's not fair, I was got onto backup for talking' [implication that if it was someone else talking this reaction wouldn't have happened]. 'Backup' is where the teacher radios for one of the roaming members of staff to come and remove the student from the classroom. (Research diary, $24^{\text {th }}$ January).

This is, in part, due to the use of RJ in the unit but not in the wider school which, combined with the lack of movement of staff between the unit and the rest of the school, meant that there was a general lack of knowledge and understanding about both the unit members and the work that was done with them in the inclusion room. Key to this was a sense that the unit members were not deserving of the ethic of care embodied in the unit. Mr Lonsdale said this sense was shared by mainstream staff and students: 
'... the biggest resistance was staff going: "I suppose the kids go for a cup of tea and a cup of hot chocolate and a nice chat and so on"'

the kids who come out of ... Inclusion, they go 'oh I went on this trip, we did this, that and the other' and the other kids go 'he's been on a bloody trip' you know ... And what the kids (and even the really bright kids) struggle to understand is (well, particularly with our Inclusion kids) $\ldots$ is the perception amongst kids that ... if you're naughty or stupid ... you get all these nice... If you just come to school and you attend regularly and you try really hard, you do not get anything (interview with Mr Lonsdale)

The IM told me that this perception was even shared by parents of unit members:

The inclusion manger told me that Simon's mum has come in to see her. She said that Simon's mum told her that Simon's family thought that they were rewarding bad behaviour in the unit. The IM said that the ethos was to value the good points of the members. (Research diary, $16^{\text {th }}$ March).

A national actor working in the area of BESD also discussed this lack of understanding of the reasons behind the need for such an ethic of care:

the reason that they do that $\ldots$ is because they haven't had proper nurture in the first place ... a lady that I worked with many, many years ago called it 'mother's knee' - the things children learn at their mother's knee before they even get to school. And what you're doing when you do that kind of nurture is putting them at mother's knee. The other children who have that at home do not need it. They might think of hot chocolate as a reward but I suspect that they wouldn't want to live in that other child's shoes the rest of the time (interview with national actor in the area of BESD education). 
Whereas the inclusion unit opens up a place of belonging which challenges the established ideologies about who can be included and valued within the school, at the same time its separation from the rest of the school positions the unit members as undeserving outsiders.

Interventions such as the conversations with the students serve to depathologise the students (as they illuminate the wider structures of inequality which are seen to be at fault). However, at the same time, because that kind of scrutiny doesn't extend across all the school's students, they arguably maintain differences between the unit members and the other pupils, and reproduce the location of these differences within the young person and their background (e.g. Peters and Jackson 2009). This difference is further reinforced as the unit members are seen to be privileged, but not deserving of that privilege. The differences between the RJ-influenced unit and the non-RJ influenced mainstream school means that, while they belong more emphatically within the unit, unit members are further excluded outside the unit. This diverts, thus diverting attention away from the way in which the school contexts themselves contribute to the constitution of socio-emotional differences.

\section{$\underline{\text { Conclusions }}$}

This chapter examines how RJ approaches have been used in order to respond to young people considered to have socio-emotional differences. This case study shows that approaches rooted in restorative justice can be beneficial in the education of children and young people with socio-emotional differences, because they enable them to spend time in school and have some successes in learning. Rather than seeing their belonging to the Inclusion Unit as a form of punishment (Kane et al. 2004: 72), or a space in which their otherwise unacceptable and problematic emotions might be corrected, the pupils generally saw the unit to provide them with a consistent and predictable setting. They benefitted from the ethic of care which characterized the relationships between adults and young people in the unit, wherein their fundamental needs were met (for example, having food and drink), and they were treated as legitimate members of the school. The work 
done within the unit plays a part in, at least temporarily, redeeming the 'intolerable' and 'impossible' bodies of the unit members (Youdell 2006), and troubles dominant understandings of children and young people with BESD (constituting them via a discourse of the person rather than solely via socioemotional differences ascribed to them).

At the same time however, the limited uptake of RJ across the school plays a part in constituting socio-emotional difference as negative, partly because misconceptions about $\mathrm{RJ}$ constituted the unit members as undeserving of the ethic of care embodied by the inclusion unit staff. This was partly due to RJ being implemented only within the contained space of the unit and not across the entire school as Thorsborne and Cameron (2001) recommend. Additionally, RJ approaches have served to locate socio-emotional differences in the young people and their families, which shifts attention away from the barriers to inclusion that exist within the school, and reproduces narratives about the irredeemability of young people understood to display socio-emotional differences. The existence of the unit means that there is little pressure to examine or rectify the practices and spaces in the mainstream school that operate to exclude these students with socio-emotional differences, because members can always be returned to the unit. In this way, the unit effectively operates as a 'spatial container of difference' (Parr and Davidson 2009 in Holt et al. 2012: 11) with the mainstream school often seeing it as a space of containment for students with socio-emotional differences. While the unit might be seen to offer a kind of sanctuary from the press of normative emotions increasingly prescribed across the spaces of mainstream education (Holt et al. 2012), it is significant that there is a need for such a sanctuary within the current system of education; demonstrating how multiple exclusions and marginalisations on the basis of emotions continue even within ostensibly 'inclusive' school settings.

The SEN institution in the UK is being overhauled with attempts to provide a more integrated approach between health, education and care, giving parents of children with SEN control over their personal budget, enhance the level of involvement and control of parents over provision, and to increase schoollevel provision. This change was outlined in the 2011 Green paper on SEN 
(DfE 2011), the follow up document (DfE 2012), and came into legislation as the Children and Families Act 2014, alongside broader changes to education policy. The Green paper questioned the usefulness of the category of BESD, setting out an agenda to reduce the numbers of young people within the category of BESD, and re-labelling the category as 'Social, emotional and mental health difficulties'. Making the argument that previously attention had been directed towards presenting behaviour (without looking at underlying causes, e.g. mental health difficulties, family problems, communication difficulties), young people for whom their background is seen to be the problem will be removed from the category. What will happen to these young people when they are removed from the SEN register is, however, left unaddressed. It remains to be seen what effects these policy changes will have on children and young people seen to have socio-emotional differences, who might be newly included or excluded from the SEN institution, or may remain within it, albeit under the new system of classification and labeling. School-based initiatives such as the one described in this chapter will inevitably form part of the response to these changes. The significant material effects of the new SEN Code of Practice on pupils with socio-emotional differences are, as yet, unknown, and demand critical attention. 


\section{REFERENCES}

Benjamin, S. (2002) The micropolitics of inclusive education: an ethnography. Open University Press, Buckingham.

Bowlby, S. Lea, J. and Holt, L. (2014) 'Learning how to behave in school: a study of the experiences of children and young people with socio-emotional differences' in Mills, S. and Kraftl, P. (eds) Informal Education and Children's Everyday Lives: Geographies, Histories and Practices, Palgrave Macmillan, Basingstoke.

Crawford, T. and Simonoff, E. (2003) Parental views about services for children attending schools for the emotionally and behaviourally disturbed (EBD): a qualitative analysis, Child: care, health and development 29: 481491.

Cresswell, T. (1996) In Place/Out of Place: Geography, Ideology and Transgression. University of Minnesota Press, Minneapolis.

Department for Education (2011) Support and aspiration: A new approach to special educational needs and disability, The Stationary Office, London.

Department for Education (2012) Statistical first release: Special educational needs in England, January 2012, The Department for Education, London.

Department for Children, Schools and Families (2008) The Education of Children and Young People with Behavioural, Emotional and Social Difficulties as a Special Educational Need. DCSF, London.

Holt, L. (2010) Young people with socio-emotional differences: theorising disability and destabilising socio-emotional norms, in Chouinard, V., Wilton, R., Hall, E., (eds) Towards Enabling Geographies: 'disabled' bodies and minds in society and space. Ashgate, Farnham, pp. 145-165.

Holt, L., Lea, J., Bowlby, S., (2012) Special units for young people on the autistic spectrum in mainstream schools: sites of normalisation, abnormalisation, inclusion, and exclusion, Environment and Planning A 44, $2191-2206$. 
Holt, L. Bowlby, S. and Lea, J. (submitted) "Everyone knows me ... I sort of like move about": Habitus, young people's embodied social capital and disability - implications for the (re)production of (in)equalities" Transactions of the Institute of British Geographers.

Jull, S. (2008) Emotional and behavioural difficulties (EBD): the special educational need justifying exclusion, Journal of research in special educational needs 8: 13-18.

Jull, S. (2009) Student behaviour self-monitoring enabling inclusion, International Journal of Inclusive Education, 13, 489-500.

Kane, J., Head, G. and Cogan, N. (2004) Towards Inclusion? Models of Behaviour Support in Secondary Schools in One Education Authority in Scotland. British Journal of Special Education, 31, 68-74.

Kane, J., Lloyd, G., McCluskey, G., Riddell, S., Stead, J. and Weedon, E., (2007)

Restorative Practices in Three Scottish Councils: Final Report of the Evaluation of the First Two Years of the Pilot Projects 2004-2006, Scottish Government, Edinburgh.

Kane, J., Lloyd, G., McCluskey, G., Maguire, R., Riddell, S., Stead, J., and Weedon, E. (2009) Generating an inclusive ethos? Exploring the impact of restorative practices in Scottish schools, International Journal of Inclusive Education, 13, 231-251.

Kauffman, J.K. (2001) Characteristics of emotional and behavioral disorders of children and youth. Prentice Hall, New Jersey, 7th Edition.

McCluskey, G. Lloyd, G. Stead, J. Kane, J. Riddell, S. and Weedon, E. (2008) 'I was dead restorative today': from restorative justice to restorative approaches in school, Cambridge Journal of Education, 38: 199-216.

McCluskey, G. Kane, J. Lloyd, G. Stead, J. Riddell, S. and Weedon, E. (2011) 'Teachers are Afraid we are Stealing their Strength': A Risk Society and 
Restorative Approaches in School, British Journal of Educational Studies, 59: 105-119.

Peters, K., and Jackson, D. (2009) Mothers' experiences of parenting a child with attention deficit hyperactivity disorder, Journal of Advanced Nursing, 65: 62-71.

Pinfold, V. (2000) 'Building up safe havens all around the world': users' experiences of living in the community with mental health problems, Health and Place, 6, 201-212.

Reed, J. (2005) Towards zero exclusion: an action plan for schools and policymakers. Institute for Public policy research, London.

Shakespeare, T. (1996) Disability, identity and difference. In Exploring the Divide, Barnes, C. and Mercer, G. (eds) The Disability Press, Leeds pp 94113.

Thorsborne, M., and Cameron, L. (2001) Restorative justice and school discipline: Mutually exclusive? In Strang, H., and Braithwaite, J. Restorative justice and civil society, Cambridge University Press, Cambridge, pp.180-194.

Watson, D. Emery, C. Bayliss, P. Boushel, M. and Mclnnes, K. (2012) Children's social and emotional wellbeing in schools. Policy Press, Bristol. Youdell, D. (2006) Impossible bodies, impossible selves: exclusions and student subjectivities. Springer, Dordrecht.

Youdell, D. (2011) School trouble: identity, power and politics in education, Routledge, Abingdon.

PHOTO 1: The inclusion room (photo: authors own) PHOTO 2: The tea making facilities (photo: authors own) 
PHOTO 3: Postitive statements about the students (photo: authors own)

PHOTO 4: Inclusion book (photo: authors own) 
